\title{
Integrated management principles and their application to healthcare systems
}

\author{
RON S. KENETT ${ }^{*}$ YIFAT LAVI ${ }^{* \star}$
}

\begin{abstract}
Purpose of the paper: The paper presents, with examples, the concept of integrated models and the general principles of integrated management, with a focus on healthcare systems.

Methodology: Several interventions designed to implement integrated management in two different healthcare systems are presented. In each case, process improvement methodology was applied to common healthcare processes.

Findings: The concept of integrating the voice of customer, the voice of workforce and the voice of the process into a cohesive managerial approach was shown relevant also in healthcare.

Research limitations: Healthcare systems consist of complex organizational structures. Managers of such organizations are often very conservative and find difficult to adopt a process point of view in order to succeed in the implementation of a comprehensive integrated model.

Research and managerial implications: The goal of integrated management is to achieve a proper balance between the needs of the customers, the satisfaction of the workforce and the performance of processes. Such a balance provides added value to the organisation stakeholders, in the wide sense.

Originality/Value of the paper: Integrated models were developed in industry and their implementation was widely tested thanks to the model generalization by Kenett (2004). The research shows how healthcare systems can benefit from integrated models by pointing out similarities and differences between healthcare and industry organizations. This permits better planning of integrated model implementation and increases the potential for success.
\end{abstract}

Key words: integrated models; integrated management; Bayesian networks; healthcare systems; planned interventions; lean sigma.

\footnotetext{
KPA Ltd., Raanana, Israel and University of Turin, Italy

e-mail: ron@kpa-group.com

** Doctoral student at the University of Turin, Italy

e-mail: yifat.lavi@studenti.unito.it
} 


\section{Introduction}

Integrated Management is an updated vision of how to manage organizations in general and health care systems in particular. Underlining the approach is a map of cause and effects with inputs generated from the voice of the customer, the voice of the workforce and the voice of the process. Combining information from these various sources supports balanced decisions aimed at achieving, simultaneously, high customer satisfaction, an enthusiastic workforce and success in performance and financial dimensions (Rucci et al., 1998; Kenett, 2004; Godfrey and Kenett, 2007; Kenett, 2009).

The combination of an integrated holistic view with a descriptive causality map is the main characteristic of integrated management models. To implement such models requires both appropriate data and the application of various tools and methodologies. Kenett (2004) discusses a general approach to integrated models and Lavi et al., (2011) combine Six Sigma, Lean Sigma, Human Sigma, Balanced Scorecards and many other methods and tools to deploy an integrated management model in healthcare. Section 2 elaborates on general cause and effect models, section 3 deals with integrated management models and section 4 with integrated models in healthcare.

Two case studies of healthcare systems are presented in section 5. Section 6 summarizes the results of the study and the final section concludes with a discussion and general remarks. The statistical tools used in the study include control charts, Bayesian networks and hypothesis testing.

\section{Cause and effect models}

Statisticians have been careful not to confuse correlation with causality (e.g. Cox, 1992). A famous example, derived from data on the size of the population of Oldenburg in Germany, and the number of observed storks in 1930-1936, demonstrates a spurious correlation due to a lurking variable: time (Box et al., 2006).

A quick evaluation of population size versus number of storks, presented in Tab. 1, seems to confirm that storks bring babies to the world. Accounting for time, reveals that the growth of the town, with more buildings and places to nest is a better explanation of the phenomena generating the data.

Tab. 1: The impact of storks on the population of Oldenburg

\begin{tabular}{|lrrrrrrr|}
\hline Year & 1930 & 1931 & 1932 & 1933 & 1934 & 1935 & 1936 \\
Population in thousands & 50 & 52 & 64 & 67 & 69 & 73 & 76 \\
Number of storks & 130 & 150 & 175 & 190 & 240 & 245 & 250 \\
\hline
\end{tabular}

Source: Box et al., 2006 
Understanding causality is a basic component of both management methodology and the scientific method. Establishment of causality relies on a combination of axiomatic thought and empirical evidence derived from observational studies and designed experiments. A review of key thinkers and writers in this area covers many centuries and continents.

Sir Francis Bacon (1561-1626) was the chief figure of the English Renaissance and an influential advocate of "active science".

He writes in Novum Organum (New Method, 1620) “... the true method of experience ... first lights the candle, then by means of the candle shows the way; commencing as it does with experience duly ordered and digested, not bungling or erratic, and from it educing axioms, and from established axioms again new experiments...".

One century later, the Scottish philosopher David Hume (1711-1776) observes that:

1. Analytical claims are product of thoughts and empirical claims are a matter of fact

2. Causal claims are empirical

3. All empirical claims originate from experience.

Two hundred years later, the $20^{\text {th }}$ century saw an increase in the attention given to the concept of causation and the role of experimentation. For example Albert Einstein (1879-1955) has stated that: "Development of Western science is based on two great achievements: the invention of the formal logical system (in Euclidean geometry) by the Greek philosophers, and the discovery of the possibility to find out causal relationships by systematic experiment", A. Einstein, April $23^{\text {rd }}, 1953$.

W. Edwards Deming (1900-1993) made the important distinction between analytical and enumerative studies (Deming, 1953). The enumerative question is "how many?", the analytic question is "why?". In a dedicated preface to the Economic Control of Quality of Manufactured Product by W. Shewhart, Deming states that: "Statistical theory, as taught in the books, is valid and leads to operationally verifiable tests and criteria for an enumerative study. Not so with an analytic problem, as the conditions of the experiment will not be duplicated in the next trial. Unfortunately, most problems in industry are analytic." By using data analysis and multidisciplinary teams, causes that were never suspected as the root cause of problems were identified and eliminated. Some industrial companies became exceptional simultaneously in their performance, financial outcomes and quality (Toyota, General Electric, Ford, Motorola etc.).

In 1986, a project designed to achieve improvements in healthcare systems was launched in the USA and titled - the national demonstration project. In their book, "Curing health care" (1990), Donald M. Berwick and Blanton A. Godfrey describe the formation of the project and its main outcomes. The main question asked in the project was - "Will it be possible to achieve improvements, as experienced by industry, also in health care systems?". 
This question was tested by forming working groups which included quality improvement experts from industry in addition to health care managers from different health care systems. The project was extremely successful and, in 1991, it lead to the foundation of IHI, the American institute for healthcare improvement (http://www.ihi.org). The national demonstration project proved that the statistical methods and managerial tools used by industry to achieve improved performance and quality can be also applied in health care systems.

The concept of integrated models presented in this paper is an evolution of this fundamental insight.

Under this approach, a structured effort is conducted to study cause and effect relationships between various sources of information. In recent years, causality in general has become a major issue in statistics. A dynamic viewpoint of causality connecting causality, mediation and time is presented in Aalen, Roysland and Gran, 2012.

A complete theory of causal diagrams, where cause and effect relationships are directly integrated into mathematical models has been proposed in the form of Bayesian networks and structural equation models (Pearl, 1995, 2000, Kenett, 2007, Kenett and Salini, 2009, Kenett and Raanan, 2010, Kenett and Salini, 2011 and Kenett, 2012). In order to address the topic of integrated management in health care systems, we invoke the application of Bayesian networks to present descriptively causality links.

Bayesian networks (BN) implement a graphical model structure known as a directed acyclic graph (DAG) that is popular in statistics, machine learning and artificial intelligence. $\mathrm{BN}$ are both mathematically rigorous and intuitively understandable. They enable an effective representation and computation of the joint probability distribution over a set of random variables. The structure of a DAG is defined by two sets: the set of nodes and the set of directed edges (arrows). The nodes represent random variables and are drawn as circles labelled by the variables names.

The edges represent direct dependencies among the variables and are represented by arrows between nodes. In particular, an edge from node $\mathrm{Xi}$ to node $\mathrm{Xj}$ represents a statistical dependence between the corresponding variables. Thus, the arrow indicates that a value taken by variable $\mathrm{Xj}$ depends on the value taken by variable $\mathrm{Xi}$. Node $\mathrm{Xi}$ is then referred to as a 'parent' of $\mathrm{Xj}$ and, similarly, $\mathrm{Xj}$ is referred to as the 'child' of Xi. An extension of these genealogical terms is often used to define the sets of 'descendants', i.e., the set of nodes from which the node can be reached on a direct path.

As an example, consider the analysis of a customer satisfaction survey. The BN analysis provides a descriptive visual causality map linking the various survey variables like satisfaction from documentation, training or service provided and target variables such as overall satisfaction; recommendation and repurchasing intentions. 


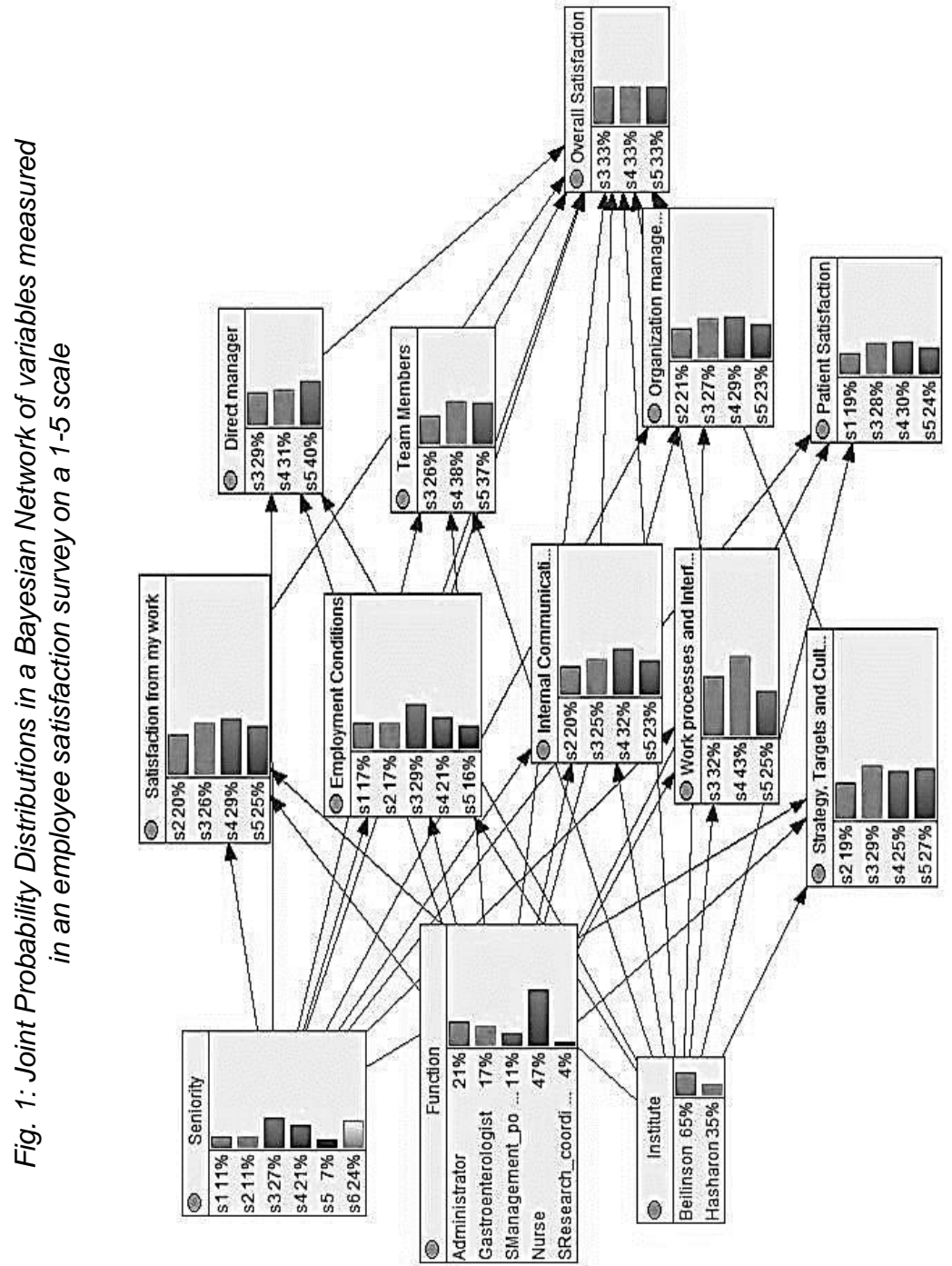

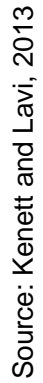

By studying the network, one can see that an intervention to improve satisfaction levels from My Work will increase satisfaction in all other topics and eventually Overall Satisfaction. As an example, consider the BN with and without conditioning on the highest satisfaction level of My Work. Without conditioning, the highest level of satisfaction from Direct Manager (percentage of " 5 ") is $40 \%$ and from Strategy, Targets and Culture is $27 \%$.

When conditioning the network on the response " 5 " to My Work as presented in Fig. 2, $40 \%$ increases to $45 \%$ and $27 \%$ increase to $32 \%$. 
The implication is that if the organization increases the percentage of employees with top level satisfaction from their direct Manager from $40 \%$ to $45 \%$ as well as their satisfaction from Strategy, Targets and Culture from 27\% to 32\%, Employees satisfaction levels from their work will increase significantly and their overall satisfaction will increase as well.

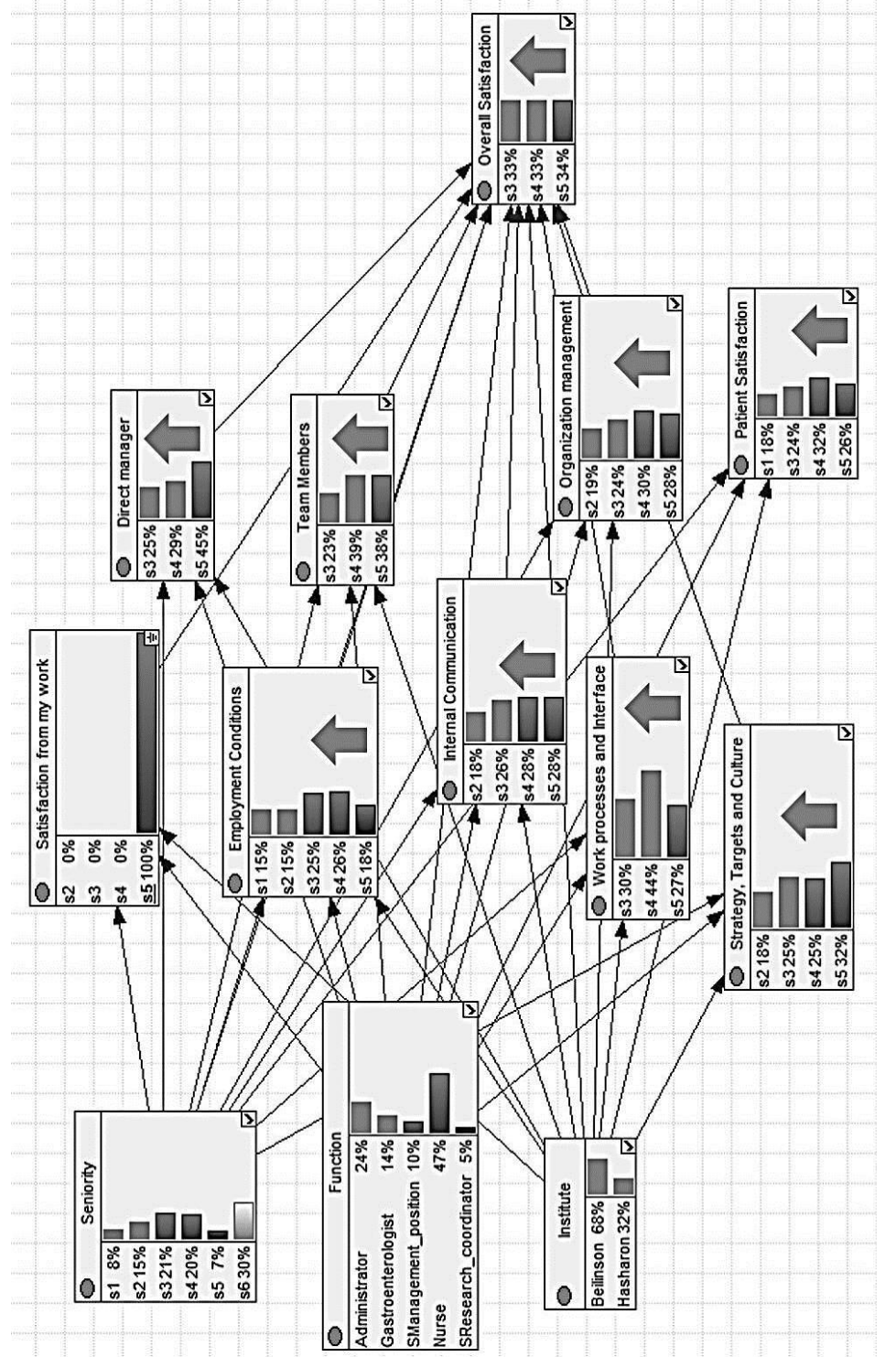


Management can learn from this analysis what actually affects their employees' satisfaction and direct future actions accordingly. For more on this data set and various models used to analyse it see Kenett and Salini (2011).

These examples show how BN can be used to analyze data derived from "passive" observational databases or from "proactive" designed experiments. Designed experiments with focused interventions are the gold standard for determining cause and effect relationships. The next sections present outcomes from interventions designed to improve healthcare services in an integrated way.

\section{Integrated management models}

The dictionary defines integration as 'the act of making a whole out of parts; the consolidation and harmonizing of parts'. Organizations are built from different part as well - People, Customers, Suppliers, Working processes and so on. These form together the whole concept of the organization - The way it produce materials, The way it gives service, How much employees enjoy working in it, How well financials are managed etc.

An early example of an integrated management model was implemented by Sears Roebuck and Co. as the employee-customer-profit model (Rucci et al., 1998). The model cause and effect chain links three strategic initiatives:

1) to be a compelling place to work;

2) to be a compelling place to shop;

3) to be a compelling place to invest.

In order to push forward these initiatives, Sears' management looked for answers to three basic questions:

1) How do employees feel about working at Sears?

2) How does employee behavior affect customers' shopping experience?

3) How does customers' shopping experience affect profits?

The model developed by Rucci et al., (1998) reflects detailed answers to these questions and identifies the drivers to improve employee retention, customer retention, customer recommendation and profits. Sears has been able to map out these variables and determine that, for them, a 0.5 increase in employee attitude could lead to a 1.3 unit increase in customer satisfaction that in turn could lead to a $0.5 \%$ increase in revenue growth.

Kenett (2004) presents a generic integrated model that has been implemented in companies in a variety of industries. The basic building block of the model is data representing:

1) Voice of the Customer;

2) Voice of the Process;

3) Voice of the Workforce

An early example of an integrated model is provided by a company specializing in HOD (Home Office Delivery) of water bottles who was able to establish that an increase in average employee satisfaction from their immediate supervisor, by 
branch, is directly related to average customer satisfaction from that branch (Kenett, 2004). In the six branches investigated, higher employee satisfaction correlates so well with higher customer satisfaction, that we can predict customer satisfaction quite closely on the basis of employee satisfaction level alone.

The implementation of integrated models consists of analyzing internal operational data, customer and employee surveys, using an interdisciplinary research teams. A brief sketch of the approach is presented in Fig. 3:

Fig. 3: A general framework for designing and implementing Integrated Models

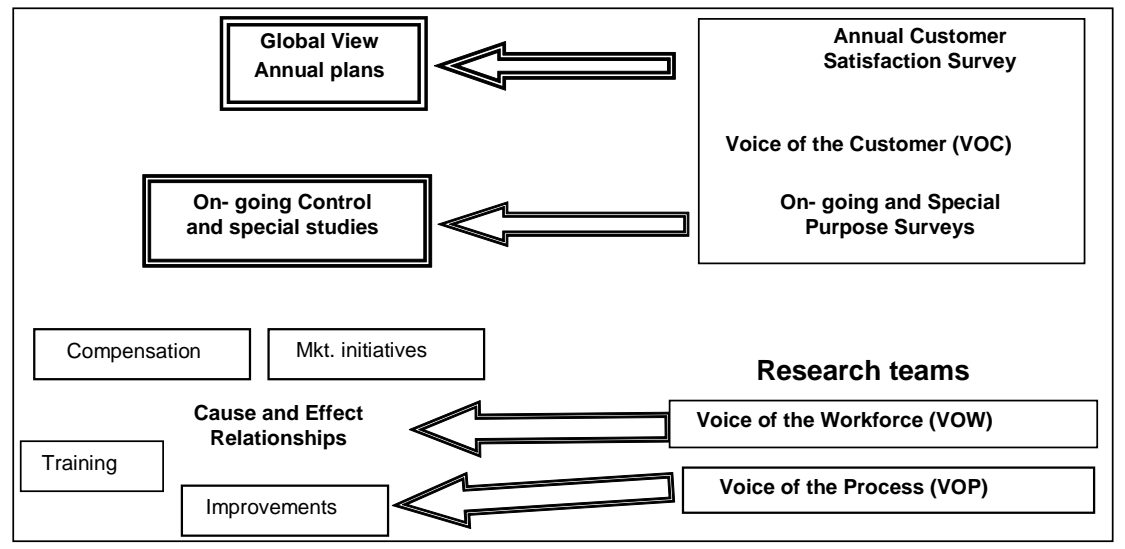

Source: Kenett, 2004

Kaplan and Norton introduced strategy maps as an improved version of their original balanced scorecards (Kaplan and Norton, 2001, 2004). A strategy map develops strategic cause and effect relationships by linking measures of financial performances to measures on their drivers. To build a strategy map the authors suggest a top down approach, starting with financial performances to be followed by cross-perspective routes leading to these performances. Norton (2004) describes the strategy map as a set of hypothetical causal relationships to be continually tested and revised and suggests testing causal linkages by means of statistical correlation analysis. However, correlation analysis is a relatively crude tool. It can only measure the strength of the relationships among performance indices and does not consider the time element involved. By contrast, techniques utilized in statistical process control seem to be more appropriate. Dror and Barad (2006) develop a validation process for dynamically investigating performance linkages as implied by a given strategy map. The proposed validation process takes into account the time dimension in performance measurement as well as the time lag between causes and their effects. Kenett (2009) shows how BNs can be used to connect Key Process Indicators and produce an effective and informative management dashboard. 


\section{Integrated management models in healthcare}

The implementation of integrated management models in healthcare systems requires special considerations and taking into account the complexity of the system. Healthcare systems are based on medical science and include treatment protocols, medical equipment, and pharmaceutical products. Healthcare management requirements impact significantly the delivery of care, beyond the various aspects of medical science.

Healthcare managers are required to also manage logistics systems as well as administrative processes. A successful healthcare manager will be able to bring the healthcare system under his control to better financial, medical and service-related outcomes. While the medical profession and the management of patients' medical condition become more and more complex, the multifaceted aspects of successful healthcare management are becoming increasingly challenging.

Modern management of healthcare systems requires a review of old work habits in parallel with the introduction of a general evidence based approach. More and more healthcare service providers consider now an integrated care model for patients, at all levels of care (primary, secondary and tertiary) in order to improve and become more effective and efficient.

An example of such an integrated care delivery model was presented by the English National Health Service (NHS) in Camden (http://www.camden.nhs.uk).

Healthcare delivery concerns the routines in hospitals, including primary patient processes, medical support processes, and nonmedical support processes. Characteristics of these processes, such as their capacity, efficiency, and reliability, determine important performance dimensions of healthcare, like throughput, patient safety, and waiting times. Ultimately, these characteristics have a substantial impact on patient satisfaction, cost, and the quality and timeliness of medical care.

Denney et al., 2009, suggest a list of key points in healthcare systems' management. These are:

1. safety;

2. effectiveness;

3. patient-centered care;

4. timelines;

5. efficiency;

6. equitable care.

These key elements play a critical role in considering an integrated model that balances out these considerations. In terms of Bayesian networks, the above six elements can be used as key process indicators that affect key system stakeholders. More and more healthcare organizations are involved in the process of designing the best way to manage healthcare systems and in defining which indicators will allow the best decision making. Two such examples are presented next.

In the context of the SiVeAS Project, the Laboratorio Management e Sanità of Scuola Superiore Sant'Anna (MeS Lab) in Pisa, Italy, developed a performance evaluation system in order to assess performance by regional healthcare services. 
The performance evaluation system proposed by MeS Lab consists of 34 indicators and 6 dimensions. The Italian Ministry of Health has charged MeS Lab to collect data and compare different healthcare institutions at the national level in Italy (http://www.salute.gov.it/siveas/siveas.jsp). This data can be used to support an integrated management model of the Italian healthcare system.

Another example of an integrated view on healthcare systems can be found in Scotland (Scottish Department of Health, 1999). Achieving integration of care services is a key policy objective of Scotland's newly devolved government and is intended to reduce the frustration, the delay, the inefficiency, and the gaps that frequently exist in care systems. While working on a development of an integrated health care system, several learning points were documented. Tab. 2 presents these key points.

Tab. 2: Learning points from the JIF in Scotland

\begin{tabular}{|c|l|}
\hline \multicolumn{2}{|c|}{ The process worked well: } \\
\hline 1. & Where there is a history of good relationships. \\
2. & Where the leadership of the Primary Care Trust is committed to making JIF work and has \\
& afforded it high priority. \\
3. & Where attention has not been diverted by other major changes/crises. \\
\hline The process was 'slow': \\
\hline 4. & Where the health Board and Trusts faced financial pressures. \\
5. & Where there is no shared vision of the JIF. \\
6. & Where the JIF is afforded low priority. \\
7. & Where there is skepticism about whether resources can be moved from the acute sector. \\
8. & Where relationships between local 'partners' were historically poor and the cultural change \\
\hline
\end{tabular}

Source: The Scottish executive department of health, 1999

In Israel, The National Quality Measures Program is an activity equivalent to the SiVeAS Project. The program began as a research project initiated by a team of researchers from Ben Gurion University, in cooperation with four Israeli HMOs. During the research stage, a unified standardized measures system was developed mainly for primary care. This enabled the establishment of a reliable and ongoing assessment of the quality of care in the community in accordance with national Israeli and international goals. In 2004 the project was adopted by the Israeli Ministry of Health and recognised as an operational national program. The program allows routine and dynamic quality assessment of the preventive, diagnostic, therapeutic and rehabilitative services supplied by the HMOs. To date, 69 indicators have been developed in six main medical fields and are regularly measured in the total Israeli population. This ongoing scientific infrastructure helps in setting national priorities during policy making and induces quality improvement. The information is also available and open to the general public providing an assessment of the quality of services in Israel (see http://www.israelhpr.org.il/e/87/67.htm).

As already mentioned, healthcare indicators can be combined using Bayesian networks described in section 2 to generate a comprehensive map of cause and effect relationship. As described in section 2, statistically designed experiments are 
also instrumental in determining cause an defect relationships (see Moore, 1993, Apfel et al., 2004, Shavit et al., 2007). Fig. 4 emphasizes the key components and their relationships in healthcare systems:

Fig. 4: A relationship diagram of care delivery components in healthcare systems

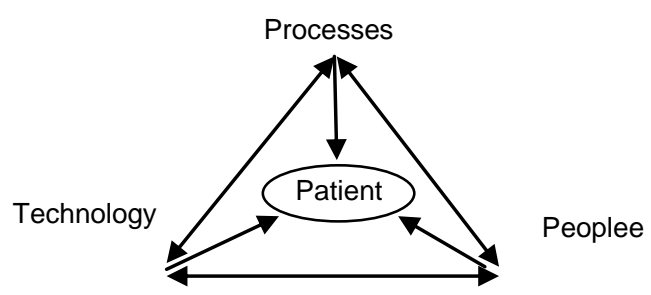

Source: Lavi et al., 2011

The triangle in Figure 4 presents the main parts of an integrated healthcare system model:

1. Processes: processes in healthcare systems vary from patients' direct treatment, such as medical check-ups, surgery, X-Ray etc. to administrative issues, such as invoicing, admission, administrative discharge etc. Lean Six Sigma can be instrumental in achieving and maintaining uniformity and best practice.

2. People: Doctors, nurses, administration staff, technicians, interns etc. are the most important resource of the healthcare system.

3. Technology: The ability of healthcare systems to deliver good service and care to patients depends on the ability to record, maintain and control patients' medical records. IT has been progressing and improving in the recent years, providing accessible solutions for performing these tasks. In addition, medical devises and modern facilities are also part of the technology dimension.

Data collection and the use of Bayesian networks allows us to investigate the link between such healthcare indicators. The next section presents two case studies in Israel where the applications of integrated models in health care have been deployed experimentally.

\section{Case studies of integrated management models in healthcare}

This section introduces the case study. More detailed results and a comparison of the case studies are presented in section 6. In planning the case studies, we combined experimental interventions with general data collection and benchmarking analysis.

\subsection{A new organization for gastroenterological professional services}

CHS is the largest Israeli healthcare system, managing over 40,000 employees, 14 hospitals and 1,200 primary and specialized clinics. As part of an overall 
organizational change, a new professional organisational unity was created in the gastroenterology department of the Dan-Petach Tiqva district and called the "gastro space". This professional space includes 3 clinics - two are located in hospitals and one in a primary care clinic in the community health service. In this district, about 60,000 patients use gastroenterology health related services in a course of a year including endoscopic procedures, consultations, surgeries etc. By creating this professional space, primary, secondary and tertiary care is managed as one integrated unit with a focus on patient optimal care and best performance.

As part of a research project held at the University of Turin, Italy, a collaboration was established with this professional space in order to define the best managerial model that will enable managing such a complex organization. Employee's satisfaction, patient satisfaction, financial data (cost of tests, retakes, procedures etc.), adverse events, patient's appointments data and clinics waiting time data for queue management was extracted from CHS databases in order to create the baseline for the research. In addition, in depth interviews were held with representatives from all organization disciplines - management, gastroenterology doctors, nurses, administrators and clinical research coordinators. The study included the following research methods:

1. Case control - performance of units of similar characteristics were used as control.

2. Benchmark - identification of units in Italy or elsewhere were used as benchmark.

3. Longitudinal assessment - the research included a before and after comparison.

The gastro space new professional structure included 3 units, which are used as gastroenterology clinics. Since they provide similar health services and have the same professional team available, it was also possible to compare them to each other. As part of the intervention, after analyzing the baseline data and interview findings, three pilot projects were defined as an intervention in the gastroenterology clinics. All projects were managed as lean sigma projects and were mentored by a professional lean facilitator:

1. Procedure room project - eliminating waste in the procedure room, as well as increasing capacity and improving patient/staff safety.

2. Appointment scheduling project - Improving the appointment scheduling process in order to reduce waiting time to the gastro clinics.

3. Patients' readiness for endoscopic procedures project - Reduce number of patients which arrive unprepared to endoscopic procedures $(\sim 20 \%)$ and are forced to redo the procedure.

As part of the intervention process, the gastro team went through a 15 hours professional lean sigma training program. Team members included gastroenterologists, nurses, administrators, clinical research coordinators and managers.

For each of the three topics, teams gathered data from IT systems in their gastro units. Data was cleaned and analyzed to create a baseline for the projects. 
The new gastro space organization management aimed to reach uniform processes and performance levels in all three units. At the first stage of the three projects, data was pulled from each unit and compared. Although it seemed like a simple task, this was one of the difficulties teams had to face. The lack of a joint database for the new organization made them pull data from three different systems and sometimes this was an impossible task due to different data format. As an example, Fig. 5 shows the waiting time to get an appointment to the gastro unit for basic consultation. In case an administrator wanted to help patients get an earlier appointment in one of the other two units, there was no way he could see availability through the IT system. Patients would have to call all three units, sometimes even schedule an appointment in all three units, and only then decide what will be their choice. This issue resulted in:

1. low satisfaction levels of patients;

2. long waiting time for telephone service centers due to calls overload;

3. an appointment No-Show rate of $30 \%$ in all units;

4. long waiting for a gastro consultation due to unnecessary scheduled appointments (when scheduling in the three units in parallel for the same patient);

5. frustration of administrators;

6. poor process performance in service indicators of CHS.

Failed preparation for colonoscopy was also one of the topics chosen for the improvement projects. Data showed differences between similar units of the organization.

Fig. 5: Analysis of data - Waiting time (in days) for gastro consultation

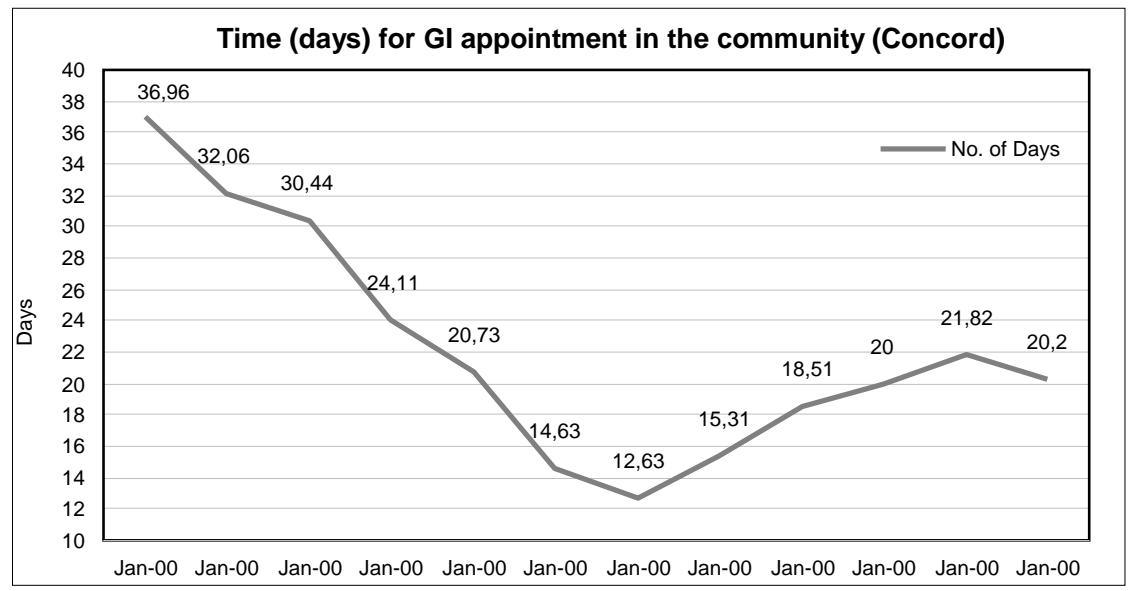

Source: Niv, 2011

Data from the third unit in the gastro space new organization is missing since there was no possibility to retrieve this information from its IT system. As Fig. 6 
shows, there were differences between the two units in failed preparation rate over the years. Failure in preparation for colonoscopy resulted in:

1. poor quality of colonoscopy results;

2. colonoscopy retakes;

3. colonoscopy cancellation;

4. patient dissatisfaction and frustration from preparation process;

5. team frustration from poor preparation;

6. late diagnosis in certain cases;

7. putting patients in risk of additional invasive testing.

An employee satisfaction survey was analysed both at the beginning and at the end of the intervention (1 year apart). Two months after the collaboration started the head of the gastro professional space left for 6 months to take part in a fellowship program in the US. As a result, projects were left without management focus, especially since the acting manager had no interest in supporting or promoting the projects. Projects started to slow down, meetings were cancelled, team members barely arrived to scheduled meetings and no manager was meeting the teams periodically in order to follow up on their goal achievement. Soon after the manager returned from his fellowship, an employee satisfaction survey was conducted and its analysis was presented and discussed with the returning manager, in order to expose the strengths and weaknesses of his organization. The manager was eventually promoted to head the hospital risk management activity which left him little time to work as the acting manager of the gastro professional space. Projects faded slowly and almost no action took place to advance any of the issues. Many lessons learned were derived from this experience. Other results from this project are presented in section 6

Fig. 6: Analysis of data - Failed preparation for Colonoscopy

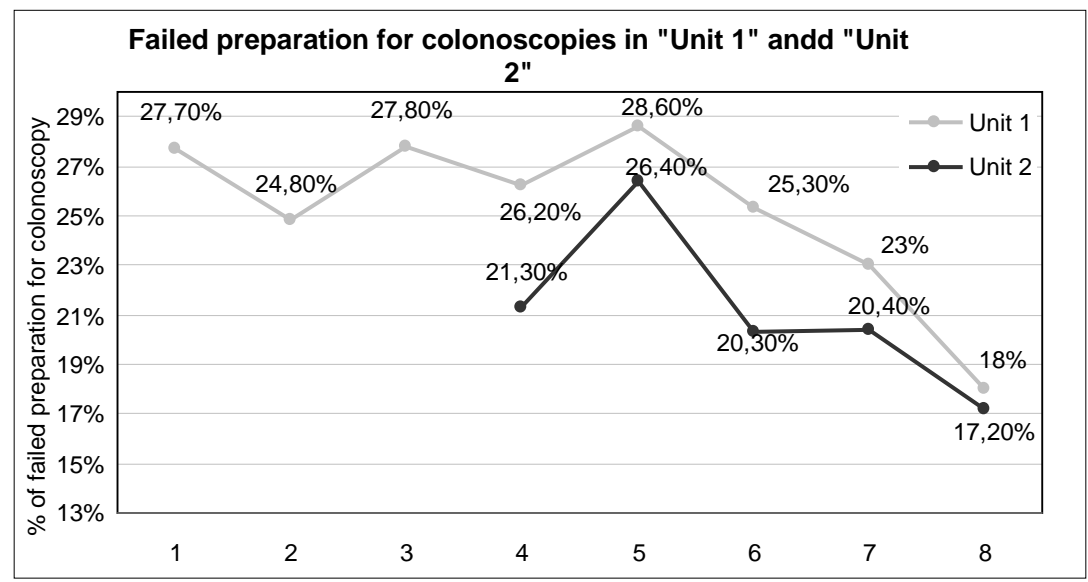

Source: Niv, 2011 


\subsection{Geriatric medical center}

"Dorot medical center", started as a Nursing Home in 1954 and was converted into a recovery medical center for third age patients. There are 365 beds in the hospital, in 12 medical wards. Main services provided at Dorot, are: acute geriatrics, nursing and complex nursing care, rehabilitation, long-term ventilation care, oncology - hospice care and a mentally frail unit. Dorot is co-managed by a CMO (Chief Medical Officer) and a CEO (Chief Executive Officer).

Dorots' Patient safety manager was looking for possibilities to engage employees into patient safety issues through joint work and data analysis. As a result, an intervention was designed in Dorot as another case study of the research on integrated models in healthcare. After two meetings with hospital management (including also the Chief Nursing Officer) with the research team, two topics were chosen for the intervention process:

1. Patients falls reduction project - Reducing patients falls in $10 \%$, without increasing chemical or physical constraints.

2. Bedsores reduction project - Eliminating occurrence of new bedsores - Reducing new occurrence of bedsores in addition to establishing a methodology for bedsores reporting and measuring.

Team members were chosen by management and the patient safety manager was appointed to lead both projects with a professional mentoring assistance. Both teams started six Sigma projects and got trainings on tools and methodology during the meetings (no formal Six Sigma/Lean training took place). Team members included Doctors, RN's, Nurse Aides, Pharmacist, Nutritionist and Patient Safety manager.

Both teams analyzed available data, performed brainstorming, used analytic tools for prioritization of tasks and concept, performed a fishbone analysis, were trained on $5 \mathrm{~S}$ concepts etc.

After completing the definition of a "Problem statement" the teams presented their work plan to a steering committee consisting of the CMO, CEO and CNO. A bi-weekly two hours meeting was scheduled for each team in order to ensure ongoing progression. Teams experienced some difficulties, facing uncooperative team members, personal relationship issues and work load, which made it hard for them to leave their work for the meetings. The CMO and CNO were updated frequently on the progress of the projects, helping solve any of the above with the best possible outcome. The teams met again the steering committee again to present their finding according to data and joint team work and suggest several improvement solutions.

As a result of this meeting, the falls reduction team finalized visual indicating characteristics of the patients so that the hospital team become more efficient and effective in handling the patient. The second team started improvements in patient handling activity in order to reduce wasted time and provide time for actions designed to reduce bedsore occurrence. 


\section{Results}

The two healthcare systems that were chosen for the intervention process have different characteristics and organizational structures. A comparison of the baseline characteristics of the two case studies is presented in Tab. 3:

Tab. 3: Case studies characteristics comparison

\begin{tabular}{|c|c|c|c|c|c|}
\hline $\begin{array}{c}\text { Case } \\
\text { Study }\end{array}$ & $\begin{array}{c}\text { Healthcare top } \\
\text { Mgt. system }\end{array}$ & $\begin{array}{c}\text { Organization } \\
\text { Seniority }\end{array}$ & $\begin{array}{c}\text { Organization } \\
\text { complexity }\end{array}$ & Main services & Acting management \\
\hline 1 & CHS - H MO & 1.5 Years & High & $\begin{array}{l}\text { Ambulatory gastro procedure and } \\
\text { consultation }\end{array}$ & Gastroenterologist \\
\hline 2 & Government & 7 Years & Low & $\begin{array}{l}\text { Rehabilitation \& hospitalization of } \\
\text { elderly patients }\end{array}$ & $\begin{array}{c}\text { Geriatric Specialist \& } \\
\text { Administrator }\end{array}$ \\
\hline
\end{tabular}

Source: Kenett and Lavi, 2013

As shown in Table 3, the two case studies are different which provides a basis for generalisation of integrated models for healthcare systems. Tab. 4 presents a summary of the results and findings discovered to date with the intervention process.

Tab. 4: Summary of intervention main results and findings

\begin{tabular}{|c|c|c|c|c|c|c|c|c|c|}
\hline $\begin{array}{c}\text { Case } \\
\text { Study }\end{array}$ & Staff & $\begin{array}{c}\text { \# of } \\
\text { planned } \\
\text { projects }\end{array}$ & $\begin{array}{c}\text { Management } \\
\text { Engagement }\end{array}$ & $\begin{array}{c}\text { Professional } \\
\text { Training }\end{array}$ & $\begin{array}{c}\text { Access } \\
\text { to data }\end{array}$ & $\begin{array}{c}\text { Quality } \\
\text { of } \\
\text { existing } \\
\text { data }\end{array}$ & $\begin{array}{c}\text { Team satisfaction } \\
\text { from the } \\
\text { intervention } \\
\text { process }\end{array}$ & $\begin{array}{c}\text { Invention } \\
\text { duration }\end{array}$ & $\begin{array}{c}\text { Current } \\
\text { Status }\end{array}$ \\
\hline 1 & 15 & 3 & Poor & Yes & Poor & Poor & $\begin{array}{c}\text { Expressed strong } \\
\text { dissatisfaction }\end{array}$ & $2011-2012$ & $\begin{array}{c}\text { Intervention } \\
\text { terminated }\end{array}$ \\
\hline 2 & 15 & 2 & Strong & No & Fair & Good & $\begin{array}{c}\text { Expressed } \\
\text { satisfaction }\end{array}$ & $\begin{array}{c}02 / 13 \text { to } \\
\text { date }\end{array}$ & $\begin{array}{c}\text { Plans for } \\
\text { further word }\end{array}$ \\
\hline
\end{tabular}

Source: Kenett and Lavi, 2013

As described in Table 4, the teams in the two organizations reached different outcomes. One could expect that a team which was trained for 15 hours of process improvement methodologies will be able to implement the knowledge gained and will be more prepared and open for changes and joint efforts. However, the interventions resulted in three teams which were not able to complete their projects and, eventually, were unhappy about the intervention process. Another point regards data availability - one of the projects in the Dorot case study lacked the data required for root cause analysis. While the team could settle for a weak analysis relying on the data they had, they performed an in depth analysis, collecting data from structured observations, employee feedback and available external data. As a result of working on the project, the team realized the importance of having good data for process control and continuous improvement.

Results from gastro space:

After two years of work, the planned intervention was terminated in the gastro space system. None of the three projects were completed and no significant improvements were achieved in the processes discussed with management at the beginning of the project.

Several major issues affected these teams: 
- the teams never met management to verify that their problem statement is aligned with organization goals for success;

- management never defined measurable success indicators;

- team meeting were not scheduled at a fixed day/time;

- no meeting room / working area was assigned for the teams to work in;

- the team members were not given suitable solution for substitutes while attending team meetings;

- community service doctors who were supposed to take part in the projects, were not officially assigned to this task.

Specific projects issues were:

Procedure room project

1. This team suffered from issues of team composition and personal relationships in the team. An assertive chief of nursing from one of the units caused many delays due to her resistance to team members' ideas and objections for changes in processes. In addition, this individual was often late to scheduled meetings, would talk on the phone during meetings and would get out when called in the middle of meetings.

2. The acting manager wouldn't help the team when some of the personal issues were reported to him. This resulted in frustration and low motivation to participate in team meetings.

3. The team observed and analyzed different processes in the procedure room and found several improvement opportunities. Pathology handling at the end of a procedure was chosen as their specific mission for improvement.

4. Due to the differences between the three units in physical structure, equipment, working processes and protocols, the teams found it difficult to progress and define a single process that fits all units.

Tab. 5 has to be advanced in the text: Benchmarking between the three gastro units

\begin{tabular}{|c|c|c|c|c|c|c|c|}
\hline Unit & $\begin{array}{c}\text { Rooms for } \\
\text { procedures }\end{array}$ & $\begin{array}{c}\text { Equipment } \\
\text { maintenance and } \\
\text { cleaning }\end{array}$ & $\begin{array}{c}\text { Cleaning } \\
\text { score }\end{array}$ & $\begin{array}{c}\text { Comfort } \\
\text { score }\end{array}$ & $\begin{array}{c}\text { Patient } \\
\text { dressing } \\
\text { room }\end{array}$ & $\begin{array}{c}\text { Transfer } \\
\text { to } \\
\text { recovery }\end{array}$ & Documentation \\
\hline 1 & 5 & RN's & 5 & 4 & Yes & 2 RN's & $\begin{array}{l}\text { Performed post procedure, medical and } \\
\text { nursing report entered in the computer, } \\
\text { pathology report and toxic registry }\end{array}$ \\
\hline 2 & 2 & $\begin{array}{c}\text { RN's / Nurse } \\
\text { Aides }\end{array}$ & 4 & 2 & No & 2 RN's & $\begin{array}{l}\text { Performed post procedure, medical and } \\
\text { nursing report entered in the computer, } \\
\text { pathology report and toxic registry }\end{array}$ \\
\hline 3 & 4 & Nurse Aides & 5 & 3 & Yes & $\begin{array}{l}\text { Performed during and post procedure, } \\
\text { medical report entered in the computer, } \\
\text { Rursing report is written manually and } \\
\text { scanned into the computer, pathology } \\
\text { report and toxic registry }\end{array}$ \\
\hline
\end{tabular}

Source: Kenett and Lavi, 2013

The table presented above demonstrates some of the gaps between the units. When team tried to address some of the issues to organization management, they were accused of presenting false data and missing projects' targets.

Appointment scheduling 
1. This team included three administrative managers from all three units. All were frustrated from their inability to do their job as good as they wished. All three were service orientated and were in good relationship between them. Having a senior gastroenterologist as a team member caused created a belligerent atmosphere towards the administrative staff.

2. The acting manager was requested to step in and help, however this was not taken care of.

3. The team worked hard in order to analyze the process of appointment scheduling, especially since the administrative staff failed to analyze the actions and kept discussing specific cases from daily work.

4. The team faced serious obstacles right at the beginning of their work and a family doctor was never assigned for this project as originally planned.

5. The new gastro space management invested much effort in appointing focal point individuals to each primary care clinic and its doctors. This analysis shows that family doctors are not using their focal points as a source of knowledge - and there is a need to understand "why?". Fig. 7 presents the analysis of the appointment scheduling process as analyzed by the team. In the process map there are indications of improvement opportunities that the team noted as next steps already at the beginning of their project.

6. Due to the different IT systems and the required assistance to recover the data, data collection was a difficult process. It was only late in the project that the team members were able to meet a family doctor which joined their meeting. In this meeting, the team realized the improvements required in the different processes are beyond their abilities since they required the engagement and support of many units in CHS. Without management intervention this could not be achieved.

Fig. 7: Scheduling appointment process map with improvement opportunities

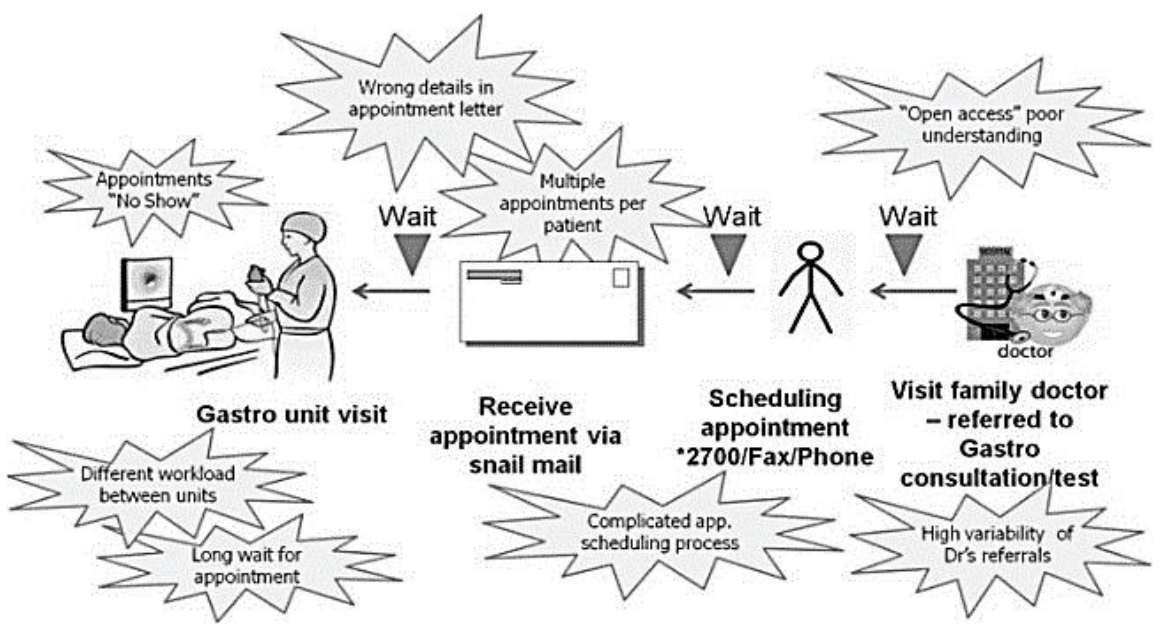

Source: Lavi, 2011 
Patients' readiness for endoscopic procedures

1. This team worked on a very problematic issue. Failed preparation for endoscopic procedures could result in the worst case even a late diagnosis of colon cancer patients. In most cases preparation quality is discovered only after procedure have started, which meant an appointment was wasted, including the waste of resources - room, equipment, medical staff time etc. Patient satisfaction was affected as a result as well, since in some cases there was a need to redo the unpleasant procedure or come back for it sooner than usually. Since patients are instructed to arrive accompanied by someone, this would mean that another persons' time was also wasted.

In Fig. 8 there is a comparison between two units from the new organization.

1. An extensive effort was undertaken in order to improve and validate the data quality and prepare it for analysis. This was another reason why the analysis was so much delayed. This delay caused frustration to team members. The team realized, while going over their data files, that system users were able to avoid filling required fields in the computerized procedure forms in addition to using their own terminology in fields designed as pull down lists. This resulted in a large variability in data and terminology of different staff members and missing data in many fields. Overtime, this team was reduced from 5 members to only the chief nursing officer and a senior gastroenterologist.

2. The analysis included several variables which were compared between the 2 clinics - Age groups - in clinic 1 patients are older $(\mathrm{F}=26,34 ; \mathrm{p}<0.001)$, Type of drug used for bowel evacuation and In-patient vs. Out-Patient comparison (no statistical significance was found).

One important variable was not analyzed - hour of procedure. This data field was not originally included in the data files and when retrieved from the database at the request of the teams, was found missing.

Fig. 8: Failed preparation proportion in two units - Jan. To Mar. 2011

Repea procedure index per Unit

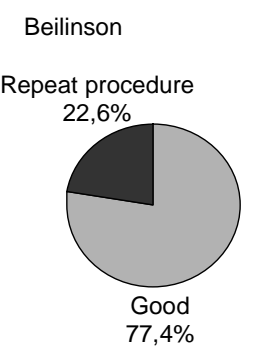

Panel variable Hospital
Pie Chart if Repeat procedure - In 2 units

Hasharon

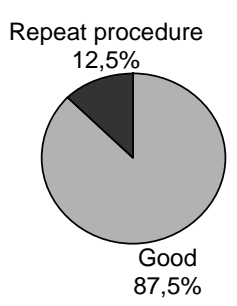

$87,5 \%$

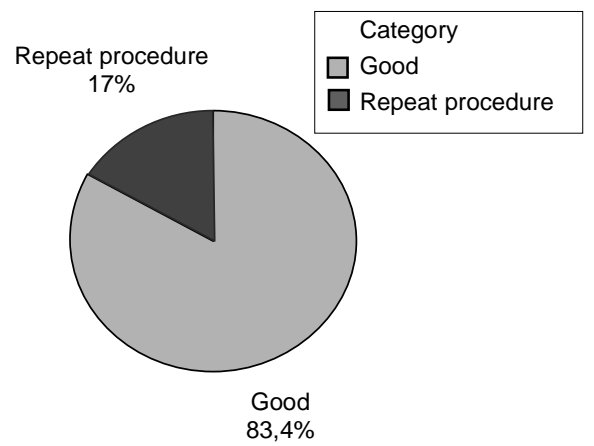


3. The team efforts were presented in a quality meeting organized by their returning manager. No actual conclusions were presented and the team stopped meeting.

\section{Employee satisfaction survey results}

At the beginning of the intervention in the gastro space organization, an employee satisfaction survey was conducted in all three clinics.

The gastro space manager sent a notice to all employees, asking their cooperation and encouraging response to it. The overall response rate was about $40 \%$.

After completing the analysis, the survey[s main findings were presented to the gastro space manager.

In comparison to other organizations the results showed that the average satisfaction level of gastro space employees were high with respect to their work team and direct manager and average on the other topics (see Fig. 9).

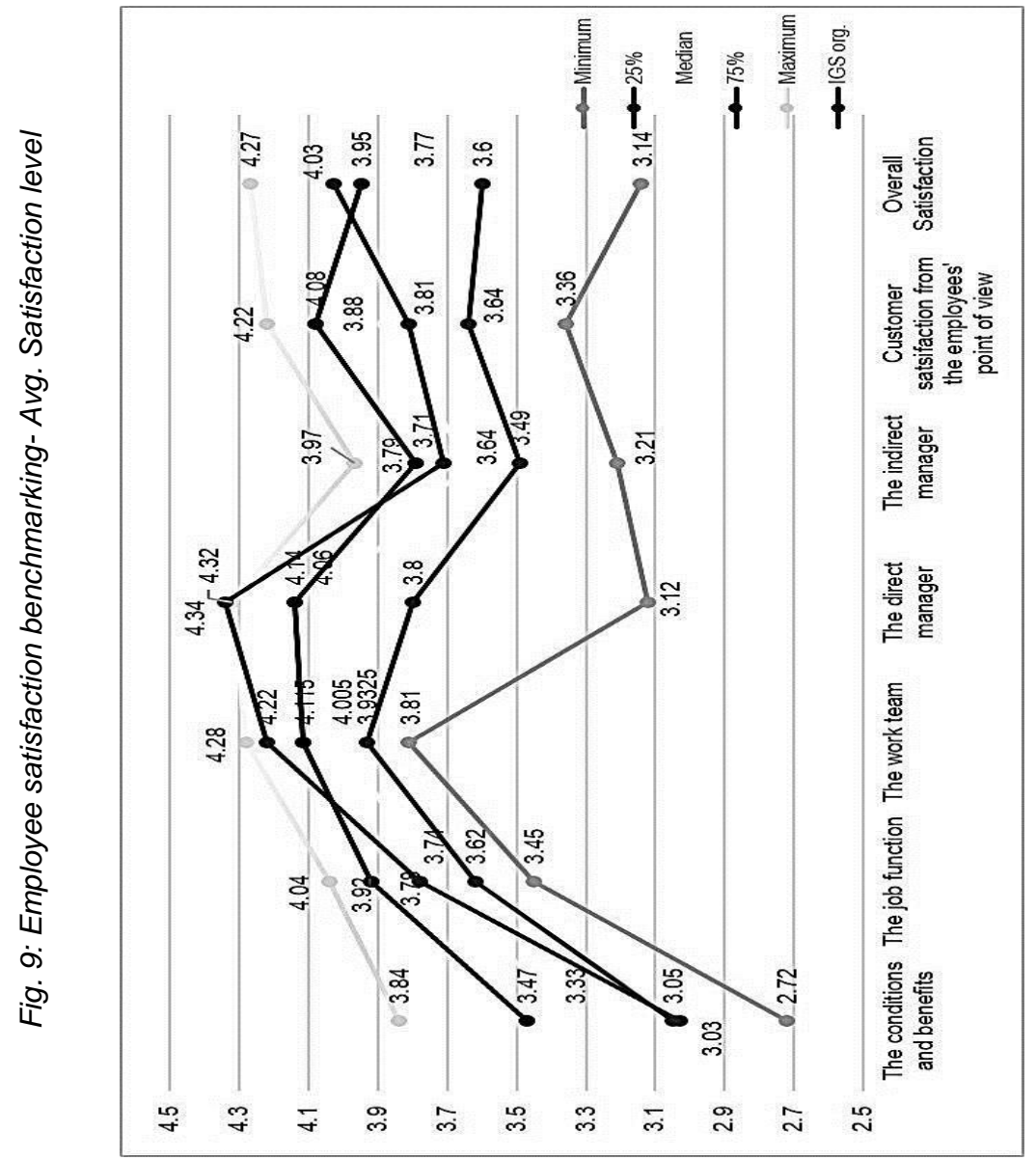


Among the topics requiring management action in the organization, two were classified as gastro space management. Specifically these were:

a. The gastro space management does not have open and sincere communication with its employees.

b. The gastro space management is unaware of daily activities and employees' daily problems during their work.

In depth interviews were performed a few months after termination of the intervention.

They indicated low satisfaction from top management support, time consumed for projects, lack of results and general frustration.

An employee satisfaction survey was performed a year after the first survey, exploring the intervention impact on employee satisfaction, in addition to the overall condition of the organization. Response rate to the survey dropped from $40 \%$ to $29 \%$. Results of 2012 survey in comparison to 2011 are described in Tab. 6:

Tab. 6: Compared results of employee satisfaction survey 2011 vs. 2012

\begin{tabular}{|l|c|c|c|c|c|c|c|c|c|c|}
\hline & $\begin{array}{c}\text { Overall } \\
\text { Satis. }\end{array}$ & $\begin{array}{c}\text { My } \\
\text { work }\end{array}$ & $\begin{array}{c}\text { Direct } \\
\text { mgr. }\end{array}$ & Team & $\begin{array}{c}\text { Emp. } \\
\text { conditions }\end{array}$ & $\begin{array}{c}\text { Internal } \\
\text { Comm. }\end{array}$ & $\begin{array}{c}\text { Strategy, } \\
\text { Targets }\end{array}$ & $\begin{array}{c}\text { Patient } \\
\text { Satis. }\end{array}$ & $\begin{array}{c}\text { Work } \\
\text { Processes }\end{array}$ & $\begin{array}{c}\text { Organization } \\
\text { Mgnt. }\end{array}$ \\
\hline $\mathbf{2 0 1 1}$ & $33 \%$ & $25 \%$ & $40 \%$ & $37 \%$ & $16 \%$ & $23 \%$ & $27 \%$ & $24 \%$ & $25 \%$ & $23 \%$ \\
\hline $\mathbf{2 0 1 2}$ & $25 \%$ & $20 \%$ & $20 \%$ & $28 \%$ & $17 \%$ & $42 \%$ & $28 \%$ & $19 \%$ & $21 \%$ & $18 \%$ \\
\hline$\Delta$ & $-8 \%$ & $-5 \%$ & $-20 \%$ & $-9 \%$ & $+1 \%$ & $+19 \%$ & $+1 \%$ & $-5 \%$ & $-4 \%$ & $-5 \%$ \\
\hline
\end{tabular}

Source: Kenett and Lavi, 2013

2011 survey data analysis indicated "Direct manager", "Work processes" and "Team members" as topics in need for immediate action. The above comparison emphasizes the fact that management did not take into consideration employees' opinion and did not invest in the right spots.

Bayesian networks were used to compare employee satisfaction data form healthcare systems in Israel and Italy. The Israeli data included employees' response to the first satisfaction survey sent to healthcare employees in the new gastro space organization.

The Italian database included employees' response from various healthcare systems in the Piemonte region in Italy from MeS Lab. In order to compare the results, the Italian survey questions were sorted into groups matching the Israeli survey main topics. 
Fig. 10: Conditioned BN comparison between Israeli and Italian healthcare systems
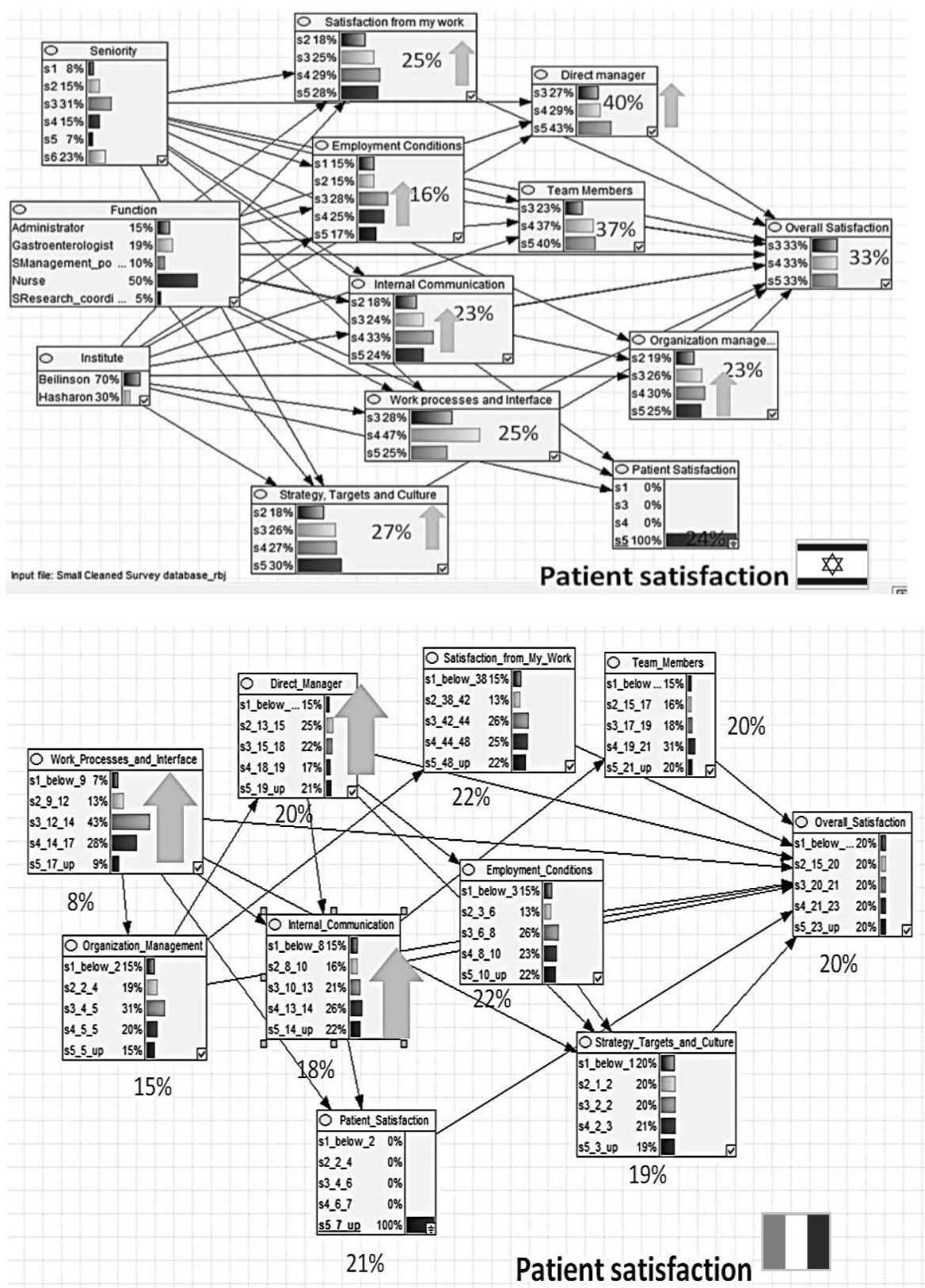

Source: Kenett and Lavi, 2013 
Fig. 10 presents a comparison between the two healthcare systems after conditioning on one of the topics - Patient satisfaction. The Israeli survey network resulted in an improvement of employees' satisfaction in six additional topics: $m y$ work $(+3 \%)$, direct manager $(+3 \%)$, employment conditions $(+1 \%)$, internal communication $(+1 \%)$, organization management $(+2 \%)$ and strategy, targets and culture $(+3 \%)$. The Italian survey network, however, resulted in an improvement of employees' satisfaction only in three additional topics: direct manager $(+1 \%)$, internal communication $(+4 \%)$ and work processes and interface $(+1 \%)$. The networks comparison presented in Figure 10 shows that in both the Italian and Israeli data, improvements in patient satisfaction in healthcare systems are achieved by improvements in employees' satisfaction from their direct manager and from organizations' internal communication. However, there are differences between the two healthcare systems in other topics.

\section{Results from Dorot projects:}

Intervention in the Dorot hospital started on February 2013 and lasted for six months. Both projects reached the "Improve" phase in their six sigma roadmap. The "Patient falls" team completed the design of a new tool, which is used like "Traffic Signs" for staff, indicating specific needs of each patient that need to be accounted for in order to prevent falling events. The "Bedsores" team started with developing a solution to nursing lost time in shifts - walking distances, lost equipment, supplies, standardized work processes etc. This helped staff improve layouts in wards and establish standard work procedures. The team started the process with complaints on shortage of suitable equipment for bedsore prevention. Initially, looking at other directions was not an option. However, thanks to a strong team leader and professional mentoring, the team discussed possible causes for bedsores occurrence and rated the causes using an analytical tool designed by KPA Ltd. Each team member listed the causes and rated them according to: Ability to Change, Required Investment and Potential Outcome. Tab. 7 presents the results of the rating process.

Tab. 7: Prioritization tool for potential causes for bedsores occurrence

\begin{tabular}{|c|c|c|c|c|c|c|c|c|c|c|}
\hline \multirow{3}{*}{$\begin{array}{cc}\mathrm{H}=\text { High } & \mathrm{M}=\text { Medium } \mathrm{L}=\mathrm{Low} \\
\text { Subject } \\
\end{array}$} & \multicolumn{9}{|c|}{ Subjects' Scoring Table } & \multirow{3}{*}{ core } \\
\hline & \multicolumn{3}{|c|}{ Ability to Change } & \multicolumn{3}{|c|}{ Required Investment } & \multicolumn{3}{|c|}{ Value Achieved } & \\
\hline & $\mathrm{L}$ & $\mathrm{M}$ & $\mathrm{H}$ & $\mathrm{L}$ & $\mathrm{M}$ & $\mathrm{H}$ & $\mathrm{L}$ & $\mathrm{M}$ & $\mathrm{H}$ & \\
\hline Patient placed in bed in a wrong position & 0 & 0 & 7 & 5 & 2 & 0 & 0 & 0 & 7 & 95 \\
\hline Patient is sitted in a wrong position & 0 & 1 & 6 & 5 & 2 & 0 & 0 & 0 & 7 & 93 \\
\hline Patient is wearing with wet cloths & 0 & 0 & 7 & 5 & 1 & 1 & 0 & 0 & 7 & 93 \\
\hline Wrong treatment protocol for patient & 0 & 0 & 7 & 2 & 5 & 0 & 0 & 0 & 7 & 88 \\
\hline Wet bed sheets & 0 & 0 & 7 & 3 & 3 & 1 & 0 & 0 & 7 & 88 \\
\hline Bed sheets are not placed properly on bed & 0 & 1 & 6 & 3 & 4 & 0 & 0 & 0 & 7 & 88 \\
\hline Loose clothing items & 1 & 1 & 5 & 4 & 2 & 1 & 0 & 0 & 7 & 83 \\
\hline Protocol is not aligned with working process & 0 & 1 & 6 & 0 & 6 & 1 & 0 & 0 & 7 & 79 \\
\hline Late instructions written in patients' protocol & 0 & 1 & 6 & 2 & 4 & 1 & 0 & 2 & 5 & 79 \\
\hline Transfusion branoulli presures skin & 1 & 1 & 4 & 6 & 0 & 1 & 0 & 1 & 6 & 79 \\
\hline Tight dressing & 0 & 2 & 5 & 2 & 3 & 2 & 0 & 0 & 7 & 79 \\
\hline Tight cloths & 1 & 1 & 5 & 4 & 2 & 1 & 1 & 1 & 5 & 76 \\
\hline Staff lacks awareness of risk factors & 0 & 1 & 6 & 0 & 5 & 2 & 0 & 0 & 7 & 76 \\
\hline Old and unupdated patients' protocols & 0 & 1 & 6 & 0 & 4 & 3 & 0 & 0 & 7 & 74 \\
\hline Reevaluation of patients' condition not performed & 0 & 1 & 6 & 2 & 3 & 2 & 0 & 3 & 4 & 74 \\
\hline
\end{tabular}

Source: Lavi, 2013 
As a result of looking at the analysis output, the team learned that other causes need to be addressed in their work, beyond the special prevention equipment which required a substantial budget. This allowed the team to progress on issues under their influence such as placing patients in the right position, scheduled position changes for patients, replacement of wet cloths etc. The team performed observations and time measurements which were analyzed and used as baseline for standard work and FTE allocation. This helped reduce wasted time and eliminate activity by staff with no added value - the outcome was better patient care and increased bedsores prevention focus. Bedsores data is now being collected regularly by a dedicated nurse and ongoing trainings of bedsores reporting and prevention are taking place. In this healthcare system management was fully engaged during the process and at a final intervention meeting with management a decision to launch more projects was made.

\section{Conclusions and discussion}

The purpose of this paper was to review the elements of integrated models and present their application in healthcare systems. Healthcare systems require a powerful model for achieving their main goal - delivering proper care to their patients in a cost effective way. To achieve this, the "delivery" process requires qualified medical staff, proper equipment, good service, efficient administrative processes, safety etc. We show here how to combine data from general health care systems at the national level with local data and plan a focused intervention.

The concept of considering the voice of customer, voice of workforce and voice of process and integrating them into a cohesive managerial approach was shown relevant also in healthcare In the two case studies presented here completely different outcomes were achieved. It was shown that if staff is given the time and encouragement to use their knowledge and expertise they will be committed and will eventually bring the organization to better performance outcomes. However, as shown by the first case study, professional tools are not enough. Without management engagement and ongoing support, the team lose interest and feel their efforts are not taken into consideration when important decisions are made. As a result of organizational changes, lack of managerial support and organizational complexity and maturity - most projects in the first case study resulted in no change of work process. Team members became disappointed from the lack of progress and the general poor quality of data.

The paper shows how to include in integrated model a mapping of mathematical causality relationships between satisfaction levels of healthcare employees, the level of patient satisfaction and the performance of processes and financial outcome. In order to validate the model structure, all variables and measurements need to be properly defined. Choosing the right indicators and using tools such as Bayesian networks for mapping cause and effect relationships is one such approach.

As mentioned at the beginning in the first section, integrated models were initially developed and implemented successfully in industrial organizations. Work 
in this research highlighted few things worth considering prior to the implementation of integrated models in healthcare organizations. A comparison of difference and similarities between industry and healthcare is described in table 8:

Tab. 8: Comparison between industrial organizations and healthcare organization

\begin{tabular}{|c|c|c|c|}
\hline \multirow[b]{3}{*}{ Management structure } & & Industry & Healthcare \\
\hline & Similar & - Organization has one manager (usually). & - Organization has one manager. \\
\hline & Different & $\begin{array}{l}\text { - Employees from all levels report to the same top } \\
\text { management. } \\
\text { - Each employee usually has one manager in } \\
\text { charge of all employment aspects - conditions, } \\
\text { professional, working hours etc. }\end{array}$ & $\begin{array}{l}\text { - Professional managers, which define policy and } \\
\text { measurements. } \\
\text { - Employees are often required to report to three } \\
\text { different managers: Professional manager, } \\
\text { Administrative manager and the organization } \\
\text { manager. }\end{array}$ \\
\hline \multirow[b]{2}{*}{ Organizational structure } & Similar & $\begin{array}{l}\text { - Departments give service to other departments. } \\
\text { - Internal communication is crucial }\end{array}$ & $\begin{array}{l}\text { - Departments give service to other departments. } \\
\text { - Internal communication is crucial }\end{array}$ \\
\hline & Different & $\begin{array}{l}\text { - Clear hierarchy from top management down to } \\
\text { - junior management levels and employees. } \\
\text { Each department is responsible for a specific } \\
\text { expertise. }\end{array}$ & $\begin{array}{l}\text { - Organizations' have complex structure with variety } \\
\text { of professional managers and sometimes even } \\
\text { several administrative managers. } \\
\text { - Hierarchy is not clear. } \\
\text { - Each department has several responsibilities and } \\
\text { same expertise can be found in more than one } \\
\text { department. }\end{array}$ \\
\hline \multirow[b]{2}{*}{ Work environment } & Similar & $\begin{array}{l}\text { Often stressing } \\
\text { Often working in shifts } \\
\text { Different between public sector and private } \\
\text { sector. }\end{array}$ & $\begin{array}{l}\text { - Often stressing } \\
\text { - Working in shifts } \\
\text { - Different between public sector and private sector. }\end{array}$ \\
\hline & Different & $\begin{array}{l}\text { - Often there are offices for different positions and } \\
\text { management levels, production lines with working } \\
\text { stations. } \\
\text { - Service is available constantly only in specific } \\
\text { - Urganization types. } \\
\text { - Usually one man is responsible on his task. }\end{array}$ & $\begin{array}{l}\text { - Almost no offices available. Clinics with multiple } \\
\text { users for patient care, sometimes patient care is } \\
\text { done behind a drape alone in a noisy and } \\
\text { stressing environment. } \\
\text { - Service is available constantly. } \\
\text { - Often patient care requires more than one person. }\end{array}$ \\
\hline \multirow[t]{2}{*}{ Rules and Standards } & Similar & $\begin{array}{l}\text { - Submitted to rules and standards (each industry } \\
\text { according to its expertise). } \\
\text { Require compliance with standards in order to } \\
\text { give service/manufacture. }\end{array}$ & $\begin{array}{l}\text { - Submitted to strict rules and standards. } \\
\text { - Require compliance with standards in order to } \\
\text { give patient care. }\end{array}$ \\
\hline & Different & $\begin{array}{l}\text { - Only certain professions require specific } \\
\text { certification }\end{array}$ & - All professional care require specific certifications \\
\hline \multirow{2}{*}{ Employment conditions } & Similar & $\begin{array}{l}\text { - Employees often feel underestimated and not } \\
\text { rewarded enough for their work } \\
\text { - Employees are evaluated by their managers and } \\
\text { peers periodically. }\end{array}$ & $\begin{array}{l}\text { - Employees often feel underestimated and not } \\
\text { rewarded enough for their work } \\
\text { - Employees are evaluated by their professional } \\
\text { managers periodically. }\end{array}$ \\
\hline & Different & $\begin{array}{l}\text { - Different levels of salaried and working terms in } \\
\text { different organizations types. } \\
\text { - Different employment conditions for different } \\
\text { management levels. }\end{array}$ & $\begin{array}{l}\text { - Different levels of salaries and working terms for } \\
\text { different professions in the same organization. }\end{array}$ \\
\hline \multirow{2}{*}{$\begin{array}{l}\text { Employees relations with } \\
\text { customers }\end{array}$} & Similar & - Indirect and direct relationships & - Indirect and direct relationships \\
\hline & Different & $\begin{array}{l}\text { - Mostly people giving consumer service to other } \\
\text { people. }\end{array}$ & $\begin{array}{l}\text { - People taking care of people in times of stress } \\
\text { and need. }\end{array}$ \\
\hline \multirow[t]{2}{*}{ Working processes } & Similar & $\begin{array}{l}\text { - Usually built from sets of repeating actions, } \\
\text { performed each product manufacturing/service } \\
\text { providing. } \\
\text { - Tasks are performed both by man and by } \\
\text { machines. } \\
\text { - Processes involve more than one employee and } \\
\text { even more than one department. }\end{array}$ & $\begin{array}{l}\text { - Usually built from sets of repeating actions, } \\
\text { performed with each patient/care giving. } \\
\text { - Tasks are performed both by man and by } \\
\text { machines. } \\
\text { - Processes involve more than one employee and } \\
\text { even more than one department. }\end{array}$ \\
\hline & Different & $\cdot$ & $\cdot$ \\
\hline \multirow[t]{2}{*}{ Use of data } & Similar & $\begin{array}{l}\text { - Each process can be measured and analyzed } \\
\text { with the right set of data. } \\
\text { - Data on processes can be: working time, cost of } \\
\text { work, \# of defected units, Qty produced etc. } \\
\text { - Data is collected either automatically into IT } \\
\text { systems or manually on paper/special files. } \\
\text { Sometimes data is neglected. }\end{array}$ & $\begin{array}{l}\text { - Each process can be measured and analyzed with } \\
\text { the right set of data. } \\
\text { - Data on processes can be: working time, cost of } \\
\text { work, \# of adverse events, Qty produced etc. } \\
\text { - Data is collected either automatically into IT } \\
\text { systems or manually on paper/special files. } \\
\text { Sometimes data is neglected. } \\
\end{array}$ \\
\hline & Different & $\begin{array}{l}\text { - Analysis of data is considered essential in many } \\
\text { industries for learning, improvement and } \\
\text { prevention. } \\
\text { - Organizations are obligated to share performance } \\
\text { results in public and are measured upon them. } \\
\end{array}$ & $\begin{array}{l}\text { - Although data is often available - many } \\
\text { healthcare organizations lack the knowledge of } \\
\text { using it for their benefit. } \\
\text { - Many healthcare organizations do not publish } \\
\text { performance results. }\end{array}$ \\
\hline \multirow{2}{*}{ Financials } & Similar & $\begin{array}{l}\text { - Budget is defined every year for organization use. } \\
\text { Cost of poor quality in processes results in high } \\
\text { costs of rework, resources etc. }\end{array}$ & $\begin{array}{l}\text { Budget is defined every year for organization use. } \\
\text { Cost of poor quality in processes results in high } \\
\text { costs of rework, resources etc. }\end{array}$ \\
\hline & Different & $\begin{array}{l}\text { - Organization financials are managed mostly by } \\
\text { the CFO, which reports to the CEO. }\end{array}$ & $\begin{array}{l}- \text { Organization financials are managed by } \\
\text { organization manager, with the support of finance } \\
\text { specialists. }\end{array}$ \\
\hline
\end{tabular}

Source: Kenett and Lavi, 2013 


\section{References}

AALEN O.O., ROYSLAND K., GRAN J.M. (2012), "Causality, mediation and time: a dynamic viewpoint", The journal of the royal statistical society, Serious A, vol. 175, Part 4, pp. 831-861.

APFEL C., KORTTILA K., ABDALLA M., KERGER H., TURAN A., VEDDER I., ZERNAK C., DANNER K., JOKELA R., POCOCK S., TRENKLER S., KREDEL M., BIEDLER A., SESSLER D., ROEWER N. (2004), "A factorial trial of six interventions for the prevention of postoperative nausea and vomiting", The New England Journal of Medicine, vol. 350, n. 24, pp. 2441-2451.

BERWICK D., GODFREY A.B., ROESSNER J. (2002), Curing health care: new strategies for quality improvement, 2nd edition, Jossey-Bass, USA.

BOX G., HUNTER W., HUNTER S. (2006), Statistics for experimenters: an introduction to design, data analysis, and model building, Second Edition, J. Wiley, Chichester, UK.

COX D.R. (1992), "Causality: some statistical aspects", Journal of the Royal Statistical Society. Series A (Statistics in Society), vol. 155, n. 2, pp. 291-301.

DEMING W.E. (1953), "On the distinction between enumerative and analytic surveys", Journal of the American Statistical Association, vol. 48, n. 262, pp. 244-255.

DENNEY W., ST. JOHN C., YOUNGBLOOD L. (2009), "Narrow healthcare quality chasm", Quality Progress, vol. 42, n. 5 pp. 38-45

DOES R.L.M.M, VAN DEN HEUVEL J., DE MAST J., NEIMEIJER G.C. (2011), "Improving quality in health care while reducing costs", The quality management forum, vol. 36, n. 3, pp. 12-15

DROR S., BARAD M. (2006), "Enhancing control charts to validate strategy maps", Quality Technology and Quantitative Management, vol. 3, n. 4, pp. 529-541.

FALTIN F., KENETT R.S., RUGGERI F. (2012), Statistical Methods in Healthcare, John Wiley and Sons, Chichester, UK.

GODFREY A.B., KENETT R.S. (2007), "Joseph M. Juran, a perspective on past contributions and future impact”, Quality Reliability Engineering International, vol. 23, n.6, pp. 653-663.

KAPLAN R., NORTON D. (2004), Strategy maps: converting intangible assets into tangible outcomes, Harvard Business School Press, Boston, MA

KENETT R.S. (2004), "The integrated model, customer satisfaction surveys and six sigma", Proceedings of the First International Six Sigma Conference, Center for Advanced Manufacturing Technologies, Wroclaw University of Technology, Wroclaw, Poland.

KENETT R.S. (2007), "Cause and Effect Diagrams", Encyclopedia of Statistics in Quality and Reliability, vol. 1, pp. 284-289.

KENETT R.S. (2009), "Managing Integrated Models: A challenge for Top Management and the Quality Manager", Galilee Annual Quality conference, Ort Braude College, Carmiel, Israel.

KENETT R.S. (2012), “Applications of bayesian networks”, European Network for Business and Industrial Statistics (ENBIS) Twelfth Annual Conference on Business and Industrial Statistics, Ljubljana, Slovenia, September 9-13th.

KENETT R.S., RAANAN Y. (2010), Operational Risk Management: a practical approach to intelligent data analysis, John Wiley and Sons, Chichester, UK.

KENETT R.S., SALINI S. (2011), Modern analysis of customer satisfaction surveys: with applications using $R$, John Wiley and Sons, Chichester: UK.

KENETT R.S., ZACKS S. (2014), Modern industrial statistics: with application in $R$, MINITAB and JMP, $2^{\text {nd }}$ edition, John Wiley and Sons, Chichester: UK. 
KENETT R.S., SALINI S. (2009), "New frontiers: bayesian networks give insight into survey-data analysis", Quality Progress, vol. 42, n. 8, pp. 31-36.

LAVI Y., KENETT R.S., CORRADETTI R., FRASER G., BALICER R., ERLICH D., NIV, Y. (2011), "Designing and deploying a healthcare professional service :case study in integrated healthcare management", Proceedings of the Eleventh ENBIS Conference, Coimbra, Portugal.

MACDONALD M., MORS T., PHILLIPS A. (2003), "Management system integration: can it be done?", Quality Progress, vol. 36 n. 10, pp. 67-74.

MOORE C. (1993), "Using experimental designs to improve clinical processes, quest for quality and productivity in health services", Conference Proceedings. Institute of Industrial Engineers, pp. 130-135.

MURANTE A.M., PANERO C., NUTI S. (2010), "The extent to which contextual effects explain the patient satisfaction with GP assistance in four Italian Regions", Conference of The Future of Primary Health Care in Europe, Pisa, Italy.

NORTON D. (2004), Building strategy maps, part two: testing the hypothesis, Harvard Business School Press.

PEARL J. (1995), “Causal diagrams for empirical research", Biometrika, vol. 82, n. 4, pp. 669-710.

PEARL J. (2000), Causality: Models, Reasoning, and Inference, Cambridge University Press, Cambridge.

PERELMAN J., SHMUELI A., CLOSON MC. (2008), "Deriving a risk-adjustment formula for hospital financing: Integrating the impact of socio-economic status on length of stay", Social Science \& Medicine, vol. 66, n. 1, pp. 88-98.

PETERSON J., KENETT R.S. (2011), "Modeling opportunities for statisticians supporting quality by design efforts for pharmaceutical development and manufacturing", Biopharmaceutical Report, American Statistical Association Publication, USA.

RUCCI A., KIM S., QUINN R. (1998), "The Employee-Customer-Profit Chain at Sears", Harvard Business Review, vol. 76, n. 1 pp. 83-97.

SHAVIT O., LESHNO M., GOLDBERGER A., SHMUELI A., HOFFMAN A. (2007), "It's time to choose the study design! net benefit analysis of alternative study designs to acquire information for evaluation of health technologies", Pharmacoeconomics, vol. 25, n. 11, pp. 903-911.

WATKINS D. (2006), "Reflections on the future of quality", Quality Progress, vol. 39, n. 1, pp. $23-28$.

WOODS K.J. (2001), "The development of integrated healthcare models in Scotland", International journal of integrated care, vol. $1, \mathrm{n} .1$ available online from: URL: http//www.ijic.org/

\section{Internet sites}

http://www.camden. nhs.uk

http://www.meslab.sssup.it/en/index.php?page =report -2010

http://magazine.amstat.org/blog/2012/11/01/pearl/. 
